\title{
Comparative Screening of Phytochemical Compounds in Scent Leaf Ocimum gratissimum Linn. (Family: Lamiaceae) and Bitter Leaf Vernonia amygdalina Del. (Family: Asteraceae) Extracts
}

\author{
R.N. Oladosu-Ajayi ${ }^{1, *}$, H.E. Dienye ${ }^{2}$, C.T. Ajayi ${ }^{1}$, O.D. Erinle ${ }^{1}$ \\ ${ }^{1}$ Department of Fisheries Technology, Federal College of Freshwater Fisheries Technology, New-Bussa (FCFFT), Nigeria \\ ${ }^{2}$ Department of Fisheries, Faculty of Agriculture, University of Port Harcourt, Nigeria
}

Copyright $\subset 2017$ by authors, all rights reserved. Authors agree that this article remains permanently open access under the terms of the Creative Commons Attribution License 4.0 International License

\begin{abstract}
The study on Phytochemical screening of the leaves of Ocimum gratissimum and Vernonia amygdalina was carried out to determine the compounds present. The result revealed the presence of alkaloids, flavonoids, steroid, tannins, and carotenoid. The best solvent of extraction for both plants recorded was the hot water followed by the cold water even though they were unable to liberate flavonoids from bitter leaf extracts. The washed bitter leaf extracts contained more alkaloids than the extracts made from the unwashed leaf though the differences were not significant (washed bitter leaf- $7.32 \%$ from hot water and 6.83\% from cold water, unwashed bitter leaf- $6.12 \%$ from hot water and $5.32 \%$ from cold water). The ethanolic extracts of bitter leaf liberated the flavonoids while the hot water was also able to liberate it from the scent leaf. Carotenoids were liberated from the extracts of both plants though the quantities were not significantly different. The study showed that bitter leaf and scent leaf contain similar antimicrobial compounds but former contains more quantity. It can be concluded that the different solvents of extraction have varying abilities to liberate these compounds and the quantities that each liberated has been ascertained.
\end{abstract}

Keywords Phytochemical, Scent Leaf, Bitter Leaf, Extract, Ethanol, Water

\section{Introduction}

Phytochemical screening is a process of tracing the medicinal value of plants constituents in some chemical substance that produce a definite physiologic action on the human body (Jigna et al., 2006; [7] Allero and Afolayan, 2006[2]). The most important of these bioactive compounds of plants are alkaloids, flavonoids, tannins, saponins, glycosides, cardenolides, bufadionolides and polyphenolic compounds (Erinle, 2012[5]). Knowledge of the chemical constituents of plants is desirable not only for the discovery of therapeutic agents but also because such information may be of value in disclosing new sources of such economic materials as tannins, oils, gum, precursors for the synthesis of complex chemical substances (Erinle, 2012[5]). Bitter leaf (Vernonia amygdalina) is gotten from the leaves attached to the stalk of a small ever-green shrub found all over Africa belonging to the family Asteraceace. The leaves of Vernonia amygdalina are green with a characteristic odour and bitter taste It is well known as a medicinal plant for diabetes and fever (Adenuga et al., 2010[1]). Vernonia amygdalina (Del.) commonly called bitter leaf is the most widely cultivated species of the genus Vernonia which has about 1,000 species of shrubs (Muanya, 2015[9]). It is vegetatively propagated by stem cutting at an angle of $45^{\circ}$ and popular in most of West Africa countries including Nigeria, Cameroon, Gabon and Congo Democratic Republic. Although most popularly used for food, it has also, been traditionally used for its medicinal properties. True to its name, bitter leaf is bitter to taste but surprisingly delicious in meals. Bitter leaf is called Omjunso in East Africa especially Tanzania, Onugbo in Igbo-Eastern Nigeria and Orugbo among the Itsekiri and Urhobo tribes in Nigeria, Ewuro (Yoruba), Etidot (Ibibio), Ityuna (Tiv), Oriwo (Edo), Chusa-doki Shiwaka (Hausa). Scent leaf, Ocimum gratissimum is an aromatic perennial herb, with erect stem, much branched, glabrous and woody at the base often with epidermic peeling in strips. Ocimum gratissimum is grown for the essential oil in its leaves and stems while engenol and to a lesser extent thymol extracted from the oil which are substitutes of clove oil and thyme oil. The essential oil possesses antibacterial properties and is also an important 
insect repellent so also are the leaves when left dry and burnt (Health Facts, 2015[7]). They are used as vegetables (Sulistiarini, 1999[12]), as spice due to its aromatic nature to spice various kinds of soup (e.g. pepper soup) and other delicious meals like porridge (Health Facts, 2015[7]). The whole plant has many applications in traditional medicine especially in Africa and India. The applications include in the treatment of ringworms, gout and fungal infections, malaria, catarrh, aches, colon pain. The juice gotten from squeezing its leaf can be used to cure several stomach related illnesses like cholera, diarrhea, dysentery, vomiting and convulsion (Health Facts, 2015[7]). Ocimum gratissimum and Vernonia amygdalina plants are known to have common phytochemical compounds which are used in traditional medicine for the treatment of several ailments and the extracts have been evaluated for their ability to stall the activities of organisms responsible for spoilage of fresh catfish (Clarias gariepinus) by extending its shelf life .(Oladosu-Ajayi et al., 2016[11]).It is against this background this study was carried to determine the quantity of the phytochemical compounds present in the extracts of scent leaf (Ocimum gratissimum) and bitter leaf (Vernonia amygdalina) and also to know which solvent of extraction contains more of the phytochemical compounds.

\section{Materials and Methods}

\subsection{Collection of Plant Materials}

The study site was located in a home stead garden inside the National Institute of Freshwater Fisheries Research (NIFFR) residential quarters in Kainji, New-Bussa, Niger state. Fresh leaves of Ocimum gratissimum and Vernonia amuglidana were collected early in the morning from a garden. The leaves were cut from a non-flowered stalk and were identified at the herbarium of the Institute

\subsection{Preparation of Bitter and Scent Leaf Extracts}

The bitter leaf (Vernonia amygdalina) and scent leaf (Ocimum gratissimum) were first separated from the stalk, rinsed with clean water to remove the dust and dirts. This was macerated and divided into two portions, one part of the bitter leaf was unwashed and the other part was washed to remove part of the juice that is responsible for the bitter taste. The extraction was done as follows according to Azu and Onyeagba (2007). [3]

1. Bitter leaf $(300 \mathrm{~g})$ was soaked in $150 \mathrm{ml}$ of $95 \%$ ethanol for 24 hours. The pulp obtained was left in clean, sterile glass container and vigorously shaken to allow for proper extraction. Filtration was done using a sterile muslin cloth after which the extract obtained was air-dried and store for use.

2. Bitter leaf $(300 \mathrm{~g})$ was soaked in $150 \mathrm{ml}$ of cold water for 24hours and the resultant juice extracted was air dried and stored as done in (1) above.

3. Bitter leaf $(300 \mathrm{~g})$ was soaked in $150 \mathrm{ml}$ of hot water for 24hours and the resultant juice extracted was air dried and stored as done in (1) above.

The scent leaf extracts were also prepared using the above procedure.

\subsection{Qualitative Analysis of Phytochemical Compounds}

Qualitative analysis was carried out to ascertain the presence of the different phytochemical compounds in the leaves. The method used and their corresponding inferences are shown below.

Table 1. Qualitative Analysis of Phytochemical Compounds

\begin{tabular}{|c|c|c|c|c|}
\hline & Phytochemical & Test & Observation & Inference \\
\hline 1 & Alkaloid & Wagner dragendroffs & Brown precipitate which turns intense yellow with the picnic acid & Alkaloid present \\
\hline 2. & Tannins & Ferric chloride & Greenish - black precipitate & Tannin present \\
\hline 3. & Flavonoid & $\begin{array}{c}\text { Ammonium and sodium } \\
\text { hydroxide acid }\end{array}$ & Yellow colour which turns colourless on addition of acid & Flavonoid present \\
\hline 4. & Steroids & $\begin{array}{c}\text { Liberman Burchard and } \\
\text { Salkowkis }\end{array}$ & Brownish colour Red colour at interference & Steroid present \\
\hline
\end{tabular}

Source: Harborne (1973) 


\section{Quantitative Analysis of Phytochemical Compounds}

Determination of Alkaloids: This was done by the alkaline precipitation gravimetric method described by Harborne, (1973) [6]. A measured weight of the sample was dispersed in $95 \%$ acetic acid solution in ethanol to form a ratio of $1: 95(95 \%)$. The mixture was allowed to stand for 24hours. The filtrate was concentrated to one quarter of its original volume by evaporation and treated with drop wise addition of concentrated aqueous $\mathrm{NH}_{4} \mathrm{OH}$ until the alkaloid was precipitated. The alkaloid precipitated was received in weighed filter paper, washed with $1 \%$ ammonia solution dried in the oven at $80^{\circ} \mathrm{c}$. Alkaloid content was calculated and expressed as a percentage of the weight of sample analysed.

Determination of Flavonoids: This was determined according to the method of Harborne (1973)[6]. 300gram of the same was boiled in $150 \mathrm{ml}$ of $2 \mathrm{~m} \mathrm{HCL}$ solution for 30 mins under reflux. It was allowed to cool and then filtered through Whatman No 42 filter paper. A measured volume of the extract was treated with equal volume of ethyl acetate starting with a drop. The flavonoids precipitated were recovered by filtration using weighed filter paper. The resulting weight difference gave the weight of flavonoids in the sample.

Determination of Carotenoids: A measured weight of each sample was homogenized in ethanol using a laboratory blender. A 1:10 (1\%) mixture was used. The homogenate was filtered to obtain the initial crude extracts. $20 \mathrm{ml}$ of ether were added to the filtrate to take up the carotenoids mixed well and then treated with $20 \mathrm{ml}$ of distilled water in a separating funnel. The other layer was recovered and evaporated to dryness at low temperature $(35-50 \mathrm{c})$ in a vacuum dessicator. The dry extract was then saponified with $20 \mathrm{ml}$ of ethanolic potassium hydroxide and left over night in a dark cupboard. The next day, the carotenoid were taken up in $20 \mathrm{ml}$ of ether and then washed with two portions of $20 \mathrm{ml}-$ distilled water. The carotenoid extract (ether layer) was dried in a dessicator and then treated with a light petroleum (petroleum spirit) and allowed to stand overnight in a freezer $\left(-10^{\circ} \mathrm{c}\right)$. The next day the precipitation steroid was removed by centrifugation and the carotenoid extracts was evaporated to dryness in a weighed evaporation dish, cooled in a dessicator and weighed. The weight of carotenoid was determined was expressed as a percentage of the sample weight (Okafor, 1987) [10].

\section{Results}

The phytochemical compounds present in the extracts of washed bitter leaf are shown in table 2. Flavonoids were absent in the hot water extracts while alkaloids, tannins and steroids are present. Also flavonoids and tannins were absent in the cold water extract while steroids and alkaloids were present. Tannins were not present in the ethanolic extract while the alkaloids, steroids and flavonoids were present. The screening of unwashed bitter leaf extract, flavonoids and steroids were absent in the hot water extract while it was only the flavonoids that were absent in the cold water extract. The ethanol extract was able to liberate flavonoids, alkaloids and tannins with the exception of the steroids. The phytochemical compounds present in the extract of washed scent leaf as shown in table 3, steroids and tannins were absent in the ethanolic extract while tannins were absent in the hot water extract. The cold water extract was able to liberate the alkaloids and steroids. The phytochemical compounds present in the extract of unwashed scent leaf. Steroids were absent in the hot water extract while only alkaloids were present in the cold water extract. The ethanolic extract showed the presence of alkaloids and tannins. The summary of the result of quantitative screening of phytochemicals present in washed bitter leaf extracts as shown in table 4.Alkaloid has the highest quantity $17.08 \%$ also flavonoids as $2.32 \%$ present in ethanolic extract only while carotenoids has $0.135 \%$ in ethanolic, cold and hot water extracts. The quantity of phytochemicals found in unwashed bitter leaf extracts was also summarizes. Alkaloids has the highest amount $14.56 \%$ in ethanolic, hot and cold water extract and flavonoids has $2.42 \%$ in ethanolic, cold and hot water extracts only followed by carotenoid which has $0.24 \%$ in ethanolic, cold and hot water extracts. Table 8 shows the quantity of phytochemical compounds in washed scent leaf extracts. Alkaloids has 5.86\% in ethanolic, cold and hot water extract which flavonoids has $3.28 \%$ in ethanolic, and hot water and not found in cold water extract and carotenoids has $0.2 \%$ in ethanolic hot and cold water extracts. The quantity of phytochemical compounds in the extracts of unwashed scent leaf is shown below in table 5 . Alkaloids has $7.82 \%$ in ethanolic, cold and hot water extracts and flavonoids $2.11 \%$ in hot water extract and not found in ethanolic and cold water extracts while carotenoids has $0.22 \%$ in both ethanol, hot and cold water extracts.

Table 2. Qualitative Screening of Washed Bitter and Unwashed Leaf Extracts

\begin{tabular}{|c|c|c|c|c|c|c|c|c|}
\hline \multicolumn{5}{|c|}{ WASHED BITTERLEAF EXTRACT } & \multicolumn{4}{c|}{ UNWASHED BITTERLEAF EXTRACT } \\
\hline & Alkaloids & Flavonoids & Steroids & Tannin & Alkaloids & Flavonoids & Steroids & Tannin \\
\hline HWE & + & - & + & + & + & - & - & + \\
\hline CWE & + & - & + & - & + & - & + & + \\
\hline EE & + & + & + & - & + & + & - & + \\
\hline
\end{tabular}


Table 3. Qualitative Screening of Washed Scent Leaf and Unwashed Scent Leaf Extracts

\begin{tabular}{|c|c|c|c|c|c|c|c|c|}
\hline \multicolumn{4}{|c|}{ WASHED SCENTLEAF EXTRACT } & \multicolumn{4}{c|}{ UNWASHED SCENTLEAF EXTRACT } \\
\hline & Alkaloids & Flavonoids & Steroids & Tannin & Alkaloids & Flavonoids & Steroids & Tannin \\
\hline HWE & + & + & - & - & + & + & - & + \\
\hline CWE & + & + & + & - & + & - & - & - \\
\hline EE & + & - & + & - & + & - & - & + \\
\hline
\end{tabular}

Table 4. Quantitative Screening of Washed Bitter Leaf and Unwashed Bitter Leaf Extract in \% (G/100g)

\begin{tabular}{|c|c|c|c|c|c|c|}
\hline \multicolumn{4}{|c|}{ WASHED BITTER LEAF EXTRACT } & \multicolumn{3}{c|}{ UNWASHED BITTER LEAF EXTRACT } \\
\hline & Alkaloids & Flavonoids & Carotenoids & Alkaloids & Flavonoids & Carotenoids \\
\hline EE & 2.93 & 2.32 & 0.045 & 3.12 & 2.42 & 0.14 \\
\hline CWE & 6.83 & -- & 0.04 & 5.32 & -- & 0.06 \\
\hline HWE & 7.32 & -- & 0.05 & 6.12 & -- & 0.07 \\
\hline TOTAL & 17.8 & 2.32 & 0.135 & 14.56 & 2.42 & 0.26 \\
\hline
\end{tabular}

Table 5. Quantitative Screening of Washed and Unwashed Scent Leaf Extract in \% (G/100g)

\begin{tabular}{|c|c|c|c|c|c|c|}
\hline \multicolumn{4}{|c|}{ WASHED SCENT LEAF EXTRACT } & \multicolumn{3}{c|}{ UNWASHED SCENT LEAF EXTRACT } \\
\hline & Alkaloids & Flavonoids & Carotenoids & Alkaloids & Flavonoids & Carotenoids \\
\hline EE & 2.56 & 1.88 & 0.10 & 1.75 & -- & 0.11 \\
\hline CWE & 1.88 & -- & 0.04 & 1.43 & -- & 0.03 \\
\hline HWE & 1.40 & 1.40 & 0.06 & 4.64 & 2.11 & 0.08 \\
\hline TOTAL & 5.86 & 3.28 & 0.2 & 7.82 & 2.11 & 0.22 \\
\hline
\end{tabular}

\section{KEY}

$\mathbf{E E}=$ Ethanolic extract

HWE $=$ Hot water extract

$\mathbf{C W E}=$ Cold water extract

SUN $=$ Scent leaf unwashed

$$
\begin{aligned}
& \text { BW = Bitter leaf washed } \\
& \text { BUN = Bitter leaf unwashed } \\
& \text { SW = Scent leaf washed } \\
& +=\text { Present }-=\text { Absent }
\end{aligned}
$$

\section{Discussion}

The results obtained from this study showed that hot water, cold water and ethanolic extracts of the plants have varying contents of the phytochemical compounds. It also shows that though the two plants contain similar phytochemical compounds, the quantities differ. The aqueous extracts of the bitter leaf contained the highest quantities of alkaloids (Tables 4 and 5). This was obvious in the washed and unwashed bitter leaf (washed: Cold water extract-6.83\% and Hot water extract-7.32\%; unwashed: Cold water extract-5.32\% and Hot water extract-6.12\%). Therefore, it can be concluded that alkaloids are more revealed in bitter leaf extract when it is washed, although an appreciable quantity can also be gotten when it is not washed. It can also be deduced from this experiment that alkaloids are not heat labile since the highest quantity was liberated from the hot water extract. The ethanolic extracts contained the least quantities (washed: $2.93 \%$ and unwashed: $3.12 \%$ ). This shows that ethanol is an organic solvent and an excellent phytochemical compound liberator; it was unable to exhibit those characteristics in the extraction of alkaloids from bitter leaf extracts. This is unlike the findings of Ephraim (2010) [4] who got more alkaloids from the ethanolic extracts of black pepper seeds and pawpaw seeds. The study also discovered that the hot water extracts of the two plants (black pepper and pawpaw seeds) liberated more alkaloids than the coldwater extracts. The carotenoids were also not well liberated by the aqueous extracts (cold and hot water). Bitter leaf (washed and unwashed) extracts contained low content of flavonoids compared to the alkaloids as shown in this result. Hot water extract retained more of the compounds compared to cold water extracts. Carotenoid levels increased in hot water extracts $0.05 \mathrm{~g} / 100 \mathrm{~g}$ while the content was reduced in cold water extracts $0.04 \mathrm{~g} / 100 \mathrm{~g}$. The resistance of carotenoid to the effect of heat is in line with the earlier report of Anderson (2002) that phytochemical compounds are not affected by processing. It can thus be said about bitter leaf that the phytochemical compounds are better liberated after washing using either the hot or cold water as solvents of extraction while the flavonoids content can only be revealed in the ethanolic extract.

This study reveals that more of the compounds were found in both scent leaf and bitter leaf.. Unlike the bitter leaf, the aqueous extracts did not liberate much alkaloids (washed: Cold water extract-1.88\% and Hot water extract-1.40\%; unwashed: Cold water extract-1.43\% and Hot water extract $-4.64 \%$ ) while the ethanolic extract liberated $2.56 \%$. 
This means that to use hot water as solvent of extraction for flavonoids, the scent leaf should not be washed while it should be washed and ethanol used as solvent of extraction when alkaloids are been screened for. Erinle (2012)[5] reported that the pigment taste of scent leaf is contributed by its high content of alkaloid. The hot water extract of the unwashed scent leaf can also be depended upon for flavonoids even though the ethanolic extract of the washed sample can also be screened for it. This result thus infers that flavonoids in the scent leaf are not well liberated and are not heat labile.

Generally, heating did not significantly affect the carotenoid content of the leaf. This indicates that carotenoid (colored pigment) remained stable during heating, though there was slight reduction in carotenoids content in ethanolic extracts and hot water extracts in the result of this study.

\section{Conclusions}

The results from this work has shown that the ethanolic, hot and cold water extracts of the plants under study contains phytochemical compounds which include alkaloids, steroids, flavonoids, carotenoids and tannins, which are responsible for their various activities and for medicinal benefits. It can be concluded that the different solvents of extraction have varying abilities to liberate these compounds and the quantities that each liberated has been ascertained. The selected plants contain substantial amount of phytochemical which are helpful in the prevention of deadly diseases. Scent leaf, (Ocimum gratissimum) and bitter leaf (Vernonia amygdalina) leaves could help fulfill the growing demands of plant based foods for human nutrition.

\section{REFERENCES}

[1] Adenuga, W.; Olaleye, O. N. and Adepoju, P. A. (2010). Utilization of bitter vegetable leaves (Gongronema latifolium, Vernonia amygdalina) and Garcinia kola extracts as substitutes for hops in sorghum beer production. African Journal of Biotechnology Vol. 9(51), pp. 8819-8823. DOI:

$$
\text { 10.5897/AJB10.1179 ISSN 1684-5315. }
$$

[2] Allero, A.A. and Afolayan, A.J. (2006). Antimicrobial Activity of Solanum tuberosum. Afri .J. Biotechnol 5:269-272

[3] Azu, N.C. and Onyeagba, R.A. (2007). Antimicrobial Properties of Extracts of Allium cepa (onions) and Zingier officinale (ginger) on Escherichia coli, Salmonella typhi and Bacillus subtilis. The Internet Journal of Tropical Medicine. 3(2). Pp 2.

[4] Ephraim, R.N. (2010). Antimicrobial Properties of extracts Carica papaya and Piper guineense on Microorganisms Associated with Catfish, Clarias gariepinus spoilage. M.Sc. Dissertation; University of Agriculture, Abeokuta (UNAAB) Ogun State, Nigeria; 87pp.

[5] Erinle, O.D. (2012). Phytochemical Screening of Scent leaf (Ocimum gratissimum) and bitter leaf (Vernonia amygdalina) extracts. ND Project, FCFFT, New Bussa, Niger State. Pp1-5

[6] Harborne, J.B. (1973). Phytochemical Methods. A guide to modern techniques of plant analysis Published in the USA by Chapman and Hall in association with Methuen, Inc. 733 Third Avenue, New York NY 10017. Pp 49-188. London, New york Chapman and Hall. Ltd

[7] Health Facts NG (2015). Health Facts. Designed by iQube Labs.www.healthfacts.ng.

[8] Jigna, P.; Nehel, K. and Sumitra, C. (2006). Evaluation of Antibacterial and Phytochemical Analysis of Bauhinia variegate L. bark. Afri. J. Biomed. Res .9 (1) 53-56

[9] Muanya, C. (2015). Scent and Bitter Leaves Retard Growth of Cancers, Boost Immune System. Guardian Newspaper Publication of $3^{\text {rd }}$ September.

[10] Okafor, J.C. (1987). Identification and Conservation of plants Used in Traditional Medicine. Lead lecture presented at the international workshop on Evaluation of Traditional Medicine; University of Nigeria, Nsukka, Nigeria. March 11-14 PP 62-68

[11] Oladosu-Ajayi, R.N.; Dienye, H.E.; Ajayi, C.T. and Agha, I.U. (2016). Vernonia amygdalina [Bitter leaf] extracts as preservative for catfish, Clarias gariepinus. International Journal of Nutritional Science and Food Technology. 3 (1). ISSN 2471-7371.pp102-108

[12] Sulistiarini, D. (1999). Ocimum gratissimum. Oyen, L.M.; Nguyen, L.P.A. and Xuan, Duan (Eds): Plant Resources of South East Asia. No 19: Essential-oils plants. Prosea foundation bojor, Indonesia. PP.140-142. 